\title{
Characterization of the Mu rhythm during the sleep of children with autism spectrum disorder level 1
}

\author{
Tania Karina García Vite,' Fructuoso Ayala Guerrero,' Erik Leonardo Mateos Salgado,' Rodolfo Cebreros Paniagua'
}

Laboratorio de Neurociencias, Facultad de Psicología, Universidad Nacional Autónoma de México, Ciudad de México, México.

\section{Correspondence:}

Tania Karina García Vite Facultad de Psicología, Universidad Nacional Autónoma de México. Ciudad Universitaria, 04510, Ciudad de México, México.

Phone: 5622 - 2222 Ext. 41243

Email: tanisws88@hotmail.com

Received: 5 September 2017

Accepted: 16 Marzo 2018

\section{Citation:}

García Vite, T. K., Ayala Guerrero, F., Mateos Salgado, E. L., Cebreros Paniagua, R. Characterization of the Mu rhythm during the sleep of children with autism spectrum disorder level 1 (previously Asperger's Syndrome). Salud Mental, 47 (3), 109-116. doi: 10.17711/SM.0185-3325.2018.017

\section{cc) (i) (5)}

\begin{abstract}
Introduction. Autistic spectrum disorder (ASD) is characterized by difficulties in communication and social interaction. The theory of mind (TM) links social deficiencies in ASD with a difficulty in representing the mental states of other people. The Mu rhythm $(8-13 \mathrm{~Hz})$ has been studied as an expression of the possible neuronal basis of TM. In ASD, the physiological reactivity of the Mu rhythm to motor events is affected. During sleep, there are also phenomena related to sensorimotor processing. Objective. To characterize the Mu rhythm in the sleep of children with level 1 ASD, ages six to 10, and compare it with control children paired by age and sex. Method. Polysomnographic records for two consecutive nights. The record of the second night was analyzed visually (the first was considered habituation) to identify and select Mu rhythm segments throughout the night. The extracted segments were analyzed using the fast Fourier transform and subsequently with $t$ tests on the data of $\mathrm{C}_{3}$ and $\mathrm{C}_{4}$. Results. A significant difference was found in the power spectrums of $\mathrm{C}_{3}$ and $\mathrm{C}_{4} t(1$, $144)=3.038, p=.003$ and $t(1,144)=-2.301, p=.023$, respectively. Discussion and conclusion. The results of this study are consistent with the morphological and topographic characteristics found in studies conducted during wakefulness. The results suggest that the Mu rhythm is caused intrinsically, without external sensory stimulation, and that there is a difference in this generation in the population with ASD.
\end{abstract}

Key words: Autism, sleep, Mu rhythm, Asperger's, quantitative, polysomnography.

\section{RESUMEN}

Introducción. El trastorno del espectro autista (TEA) se caracteriza por dificultades en la comunicación e interacción social. La teoría de la mente (TM) vincula las deficiencias sociales en el TEA con una dificultad para representar los estados mentales de otros. El ritmo $\mathrm{Mu}(8-13 \mathrm{~Hz})$ se ha estudiado como expresión del posible fundamento neuronal de la TM. En el TEA, la reactividad fisiológica del ritmo Mu a eventos motores se ve afectada. Durante el sueño también hay fenómenos relacionados con el procesamiento sensomotor. Objetivo. Caracterizar el ritmo Mu en el sueño de niños con TEA nivel 1, en edades de seis a 10 años, y compararlo con niños control pareados por edad y sexo. Método. Registros polisomnográficos durante dos noches consecutivas. Se analizó visualmente el registro de la segunda noche (la primera se consideró de habituación) para identificar y seleccionar segmentos de ritmo Mu a lo largo de ella. Los segmentos extraídos fueron analizados por medio de la transformada rápida de Fourier y posteriormente con pruebas $t$ sobre los datos de $\mathrm{C}_{3}$ y $\mathrm{C}_{4}$. Resultados. Se encontró una diferencia significativa en los espectros de potencia de $\mathrm{C}_{3}$ y $\mathrm{C}_{4} t(1,144)=3.038, p=.003$ y $t(1,144)=-2.301, p=.023$, respectivamente. Discusión y conclusión. Los resultados de este estudio son consistentes con características morfológicas y topográficas encontradas en estudios hechos durante la vigilia. Los resultados sugieren que el ritmo Mu se estaría generando de manera intrínseca, sin estimulación sensorial externa, y que existe una diferencia en esta generación en población con TEA.

Palabras clave: Autismo, sueño, ritmo Mu, asperger, cuantitativo, polisomnografía. 


\section{INTRODUCTION}

Autism spectrum disorder (ASD) is characterized by persistent impairments in communication and social interaction across multiple contexts, including deficits in social reciprocity, nonverbal communication behaviors, and developmental skills, and the maintenance and understanding of relationships interpersonal manifestations that manifest themselves in early childhood (American Psychiatric Association, 2013). The DSM-5 makes a distinction according to the severity of the symptoms, placing them at levels 1,2 , or 3 . Since the new classification incorporates DSM-IV developmental disorders, the characteristics of the DSM-Asperger's syndrome IV now correspond to level 1 of the autism spectrum in the DSM-5.

As a theoretical concept, the theory of mind (TM) states that the behavior of other people is predictable on the basis of the ability to understand their feelings, intentions, and beliefs (Tirapu-Ustárroza, 2007). Within the study of ASD, patients with autism do not have a correct functioning of this ability. For this reason, they do not understand the behavior of other people, which causes them confusion, anxiety, and inappropriate behavior when interacting with others. Within this context, researchers have sought a possible neuronal basis related to the ability to understand the mental state of others people by studying the activation of brain regions crucial to the representation of one's own experience of those states.

The ability to activate these regions is based on the ability to imitate the actions observed in other people (Hauswald, Weisz, Bentin, \& Kissler, 2013). The modulation of electroencephalographic (EEG) and neuromagnetic activities on somato-sensorial regions found within the alpha frequency range $(8-13 \mathrm{~Hz})$ called the $\mathrm{Mu}$ rhythm has been reported (Hauswald et al., 2013). This rhythm has been studied during the person's own motor execution as well as during the observation of actions performed by other people (Hari \& Salmelin, 1997). It has been postulated that the $\mathrm{Mu}$ rhythm is related to the handling of social abilities, as a result of which its functional deficiency in patients with ASD provides an explanation for some of the difficulties in social interaction reported in this population (Bernier, Dawson, Webb, \& Murias, 2007).

Likewise, various authors have suggested a functional relationship between mirror neurons and the Mu rhythm (Braadbaart, Williams, \& Waiter, 2013; Hamilton, 2013; Oberman et al., 2005; Oberman, Ramachandran, \& Pineda, 2008; Pineda \& Hecht, 2009; Pineda, 2005; Ramachandran \& Oberman, 2006; Rizzolatti \& Craighero, 2004; Williams et al., 2006), where the Mu rhythm reflects a descending modulation from the motor cortex by prefrontal mirror neurons (Pineda, 2005), which are involved in imitation, learning, and the ability to understand the actions of others (Rizzolatti \& Craighero, 2004).
At the same time, sleep is crucial to adequate brain maturation since its benefits during childhood impact the physical development and cognitive processes of the individual (Dahl, 1996; Frank, Issa, \& Stryker, 2001). In children with ASD, sleep disorders have been described in various studies, of which insomnia is one of the most commonly reported problems (Ayala-Guerrero, Mexicano, \& Huicochea-Arredondo, 2014; Cortesi, Giannotti, Ivanenko, \& Johnson, 2010; Johnson, Giannotti, \& Cortesi, 2009; Malow et al., 2006; Richdale, 1999; Souders et al., 2009; Vriend, Corkum, Moon, \& Smith, 2011; Wiggs \& Stores, 2004). The prevalence of problems reported in the sleep of children with ASD ranges from $40 \%$ to $80 \%$ (Cortesi et al., 2010). When these sleep alterations have been identified and treated, improvements have been reported in diurnal symptoms; the opposite effect is observed when sleep quality deteriorates (Malow et al., 2006; Schreck, Mulick, \& Smith, 2004).

In addition to its importance in development, there are other phenomena that occur during sleep that are relevant to the study of autism. It has been suggested that sensory motor processes may be active during REM sleep. For example, in patients with behavioral disturbance of REM sleep, people act out their dreams and are capable of reacting to stimuli in the environment while they are asleep (Duntley, Kim, Silbergeld, \& Miller, 2001). Due to the association between the $\mathrm{Mu}$ rhythm and sensorimotor processes and the decreased reactivity during wakefulness of people with ASD, it is important to explore this rhythm during the sleep of this population, in which there are also abnormalities compared to the population with typical development.

According to the rule of excitatory response in the brain, if a brain structure can generate intrinsic activity in a set frequency channel, then this structure is also able to response to sensory stimulation in the same frequency channel (Yordanova \& Kolev, 1997). Having established the above, studying this rhythm in the spontaneous sleep EEG allows us to observe the activity without external stimulation, which will provide a better understanding of its response to external stimuli.

It has been established that the physiological reactivity of Mu during wakefulness differs in samples of patients with ASD (Oberman et al., 2005; 2008; Ramachandran \& Oberman, 2006). However, when they are awake, sensory information passes through multiple channels during processing to generate this reactivity. Observing the $\mathrm{Mu}$ rhythm during sleep would provide more information about its spontaneous generation in order to determine whether differences are generated intrinsically or whether there is any alteration in the way sensory information is being processed.

Given the importance of sensorimotor processing in imitation and learning (elements in which there are flaws in autism), the role of the Mu rhythm as a reflection of these processes, as well as the impact of sleep on the development and symptomatology of autism, the purpose of this paper is 
to characterize the $\mathrm{Mu}$ rhythm in the sleep of children with level 1 autism spectrum disorder (formerly Asperger's syndrome), between the ages of six and 10 years and compare it with control children matched by age and sex.

\section{METHOD}

\section{Study design}

Cross-sectional case-control study.

\section{Sample description}

The sample consisted of 10 children with ASD and seven children with typical development (TD) within a range of six to 10 years. For the sample size, previous studies on autism and sleep carried out with polysomnography were used as reference (Malow et al., 2006), and the Mu rhythm (Bernier, Aaronson, \& McPartland, 2013; Lepage \& Théoret, 2006; Oberman et al., 2005).

The inclusion criteria for the groups were as follows:

ASD: Having a multiaxial diagnosis of ASD conducted by psychologists from the Caritas de Amistad association according to DSM-IV and DSM-5 criteria through an interview with parents and children.

TD: Sex- and age-matched with a member of the ASD group.

For all participants, informed consent was obtained from the parent or tutor.

Exclusion criteria for TD group were as follows:

Observation of any sleep disturbance during the habituation night or one that had been previously diagnosed, taking medication, previous diagnosis of a chronic disease, or health problems that will impact sleep at the time of registration. Failure to complete two nights of PSG.

ASD: Failure to complete two nights of PSG.

\section{Location}

For the participants of the group with ASD, sampling was performed by voluntary participants in the Caritas de Amistad association. Conversely, the DT group was obtained via network sampling.

\section{Procedure}

Data collection was carried out at the Laboratorio de Neurociencias from the Facultad de Psicología at the Universidad Nacional Autónoma de Mexico (UNAM) during the period from September 2013 - December 2014. Two eight-hour polysomnographies were performed for two consecutive nights, in which an electroencephalogram (EEG), an electrooculogram (EOG), and an electromyogram (EMG) were obtained. Respiratory and cardiac activity (ECG) and the percentage of circulating $\mathrm{O}_{2}$ were also obtained. The Easy II 32-Channel Amplifier and software from Cadwell Laboratories were used.

The first night was regarded as habituation and the second as the data collection night. The referrals for night 1 were: $\mathrm{C}_{3}, \mathrm{C}_{4}, \mathrm{O}_{2}, \mathrm{O}_{1}$; and for night $2: \mathrm{F}_{3}, \mathrm{~F}_{4}, \mathrm{C}_{3}, \mathrm{C}_{4}, \mathrm{~T}_{3}, \mathrm{~T}_{4}, \mathrm{P}_{3}$, $\mathrm{P}_{4}, \mathrm{O}_{1}, \mathrm{O}_{2}$. During the second night, no sensors were included for respiratory activity. During the physiological calibration, the participant was asked to perform a physical exercise to obtain the basic reactivity of the Mu rhythm.

\section{Measures used}

For the EEG on both nights, the assembly was bipolar, with $35 \mathrm{~Hz}$ high pass filters and .53Hz low pass filters and a sensitivity of $10 \mu \mathrm{V} / \mathrm{mm}$. The EEG segments identified as the $\mathrm{Mu}$ rhythm were exported in EDF format and converted to ASCII format to obtain the power spectrum. In the Fast Fourier Transformation (FFT), the following bands were established: $1-3 \mathrm{~Hz}, 4-7 \mathrm{~Hz}, 8-13 \mathrm{~Hz}, 14-18 \mathrm{~Hz}, 19-24 \mathrm{~Hz}$, and $25-30 \mathrm{~Hz}$.

\section{Data analysis}

Data analysis was performed in two stages: first, a visual examination of the EEG signal was conducted to identify and mark the different sleep phases, as well as the presence of the $\mathrm{Mu}$ rhythm. In relation to the Mu rhythm segments, the following criteria were taken into account: 1 . that the EEG fragment complied with the morphology, frequen$\mathrm{cy}$, and topographic distribution characteristics of the $\mathrm{Mu}$ rhythm; 2. that the Mu wave train had a duration of at least two seconds; and 3. that it was free of artifices.

Once the above criteria had been complied with and in order to corroborate that the selected segments belonged to the desired frequency band, the power spectrum and the correlation of segments was obtained through a FFT performed using Potencor software (Guevara, Ramos, Hernández-González, Zarabozo, \& Corsi-Cabrera, 2003). Only the segments whose activity was greater in the $8-13 \mathrm{~Hz}$ band for the $\mathrm{C}_{3}$ and $\mathrm{C}_{4}$ electrodes were kept (the area where the Mu rhythm is concentrated) (Bernier et al., 2007; Hari \& Salmelin, 1997; Pineda, 2005).

Of the files that met the previous requirement, the absolute band (ABS), which indicates the amount of EEG activity in a given band without relating it to the other bands, was analyzed. This method makes it possible to interpret the variations in a specific frequency band (Pivik et al., 1993).

\section{Statistical analyses}

In order to determine the differences between the power spectrum of the Mu rhythm $(8-13 \mathrm{~Hz})$ of the groups, two $t$ tests were carried out for independent groups on the data 


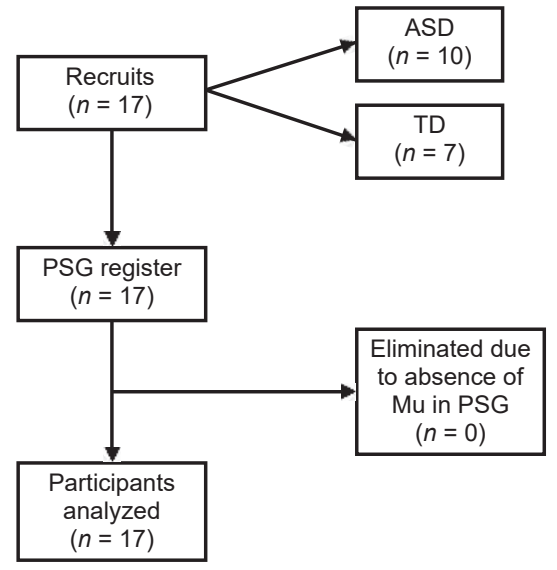

Figure 1. Participant flow.

Note: $n=$ number of participants; ASD = Autistic Spectrum Disorders; TD = Typical Development; PSG = Polysomnography.

obtained from the FFT in the absolute band of the segments with the highest activity in the $8-13 \mathrm{~Hz}$ band. In other words, a $t$ test for $\mathrm{C}_{3}$ data comparing the ASD and TD group, and for $\mathrm{C}_{4}$ data. In addition, Levene's test was performed in both cases to determine whether there was homogeneity of variance. All data analyses were performed using the IBM SPSS STATISTICS Version 20 statistical package.

\section{Ethical considerations}

For each participant, informed consent was obtained from parents and children.

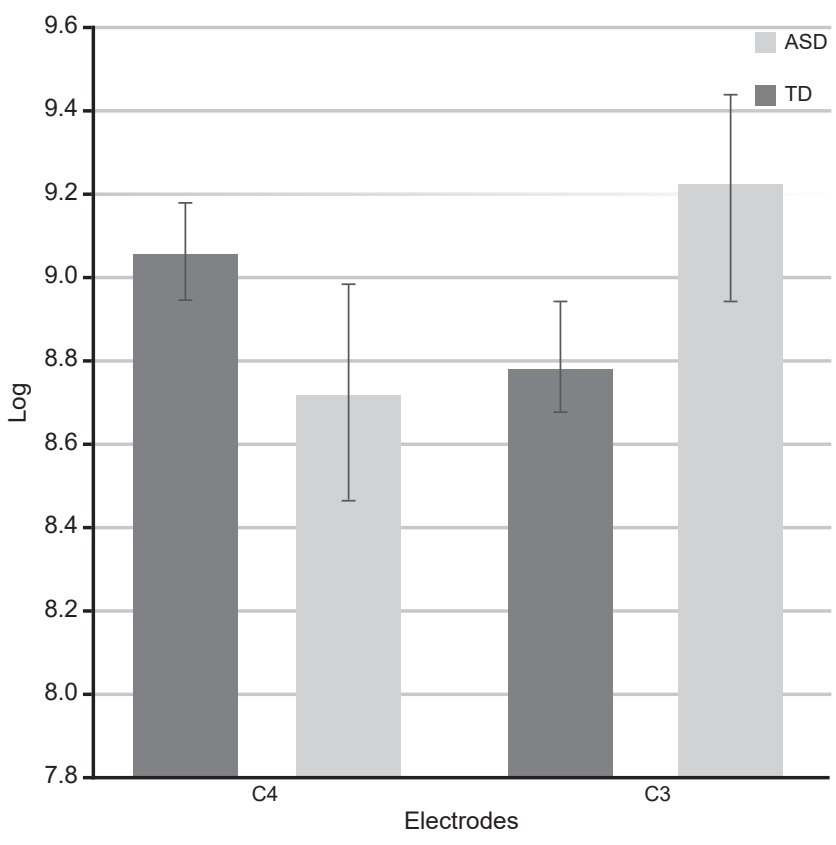

Figure 2. Differences in power spectrum of $8-13 \mathrm{~Hz}$ band according to $t$ tests.

Note: The comparison of means between the ASD group and the control group for $\mathrm{C}_{3}$ (left hemisphere), and the left side, for $\mathrm{C}_{4}$ (right hemisphere) is shown on the right side. In both cases there is a significant difference between the means. The * represent significant differences. Standard error is marked on each bar.

\section{RESULTS}

The final sample comprised 10 male participants for the ASD group and seven for the TD group, the mean age being

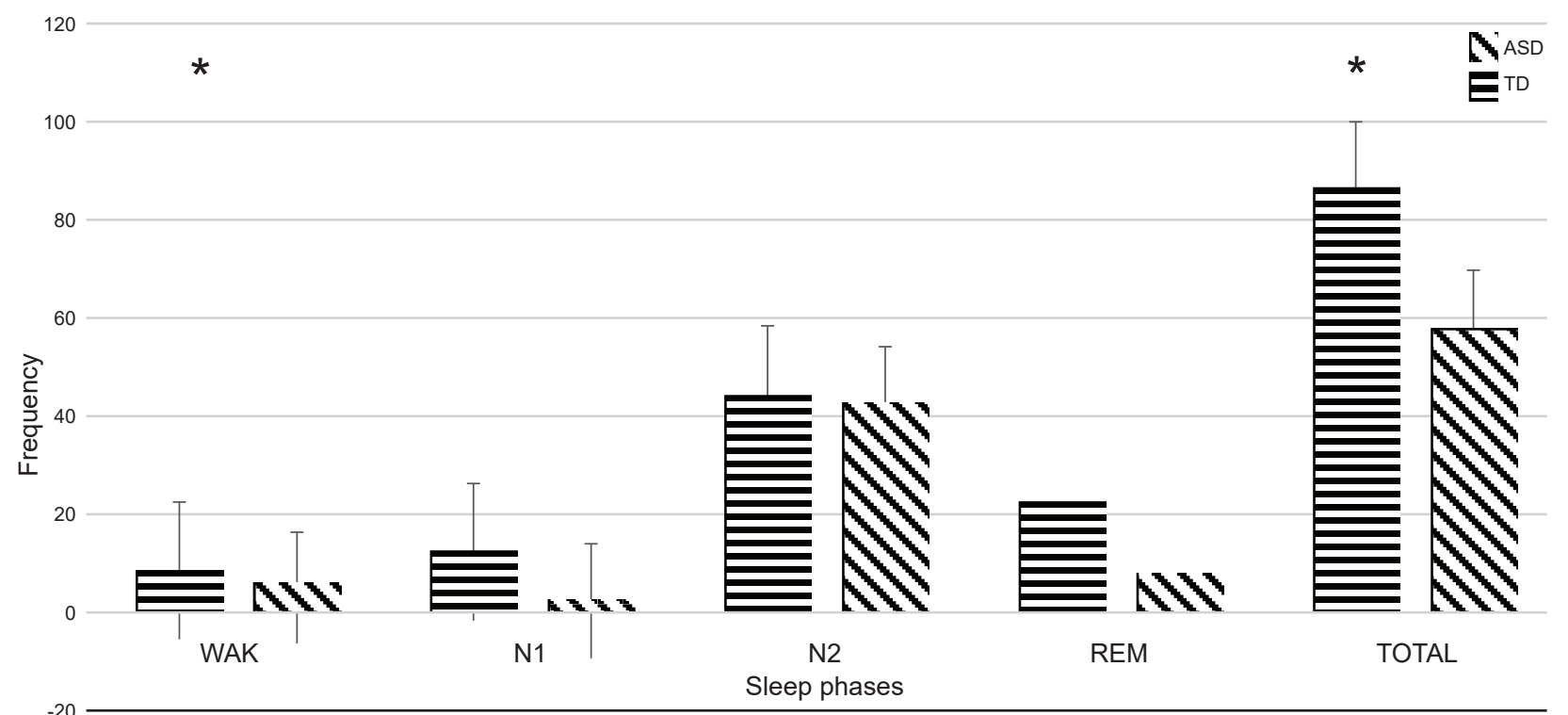

Figure 3. Frequency of the Mu segment during the night.

Note: Distribution of Mu segments identified in the various sleep phases. The frequency of segments is plotted on the vertical axis shows while the sleep phases in which they were identified are plotted on the horizontal axis. N3 is not shown because no Mu segments were identified during this phase. The horizontal stripes represent the control group and the diagonal ones represent the ASD group. Standard error is marked on each bar. WAK $=$ Wakefulness; N1, N2 = Phase N1 and N2 of sleep; REM = Rapid eye movement sleep phase. 
8.2, $(S D=1.23)$ and $8.3(S D=1.59)$, respectively. Figure 1 shows the flow of participants.

The results of the $\mathrm{t}$ tests for independent groups in $\mathrm{C}_{3}$ and $\mathrm{C}_{4}$ were $t(1,144)=3.038, p=.003$ and $t(1,144)=$ $-2.301, p=.023$, respectively. The Levene's tests were not significant, since they showed homogeneity of variances (Figure 2).

Figure 2 also shows the differences in hemispheric dominance between the groups; whereas in the TD group there

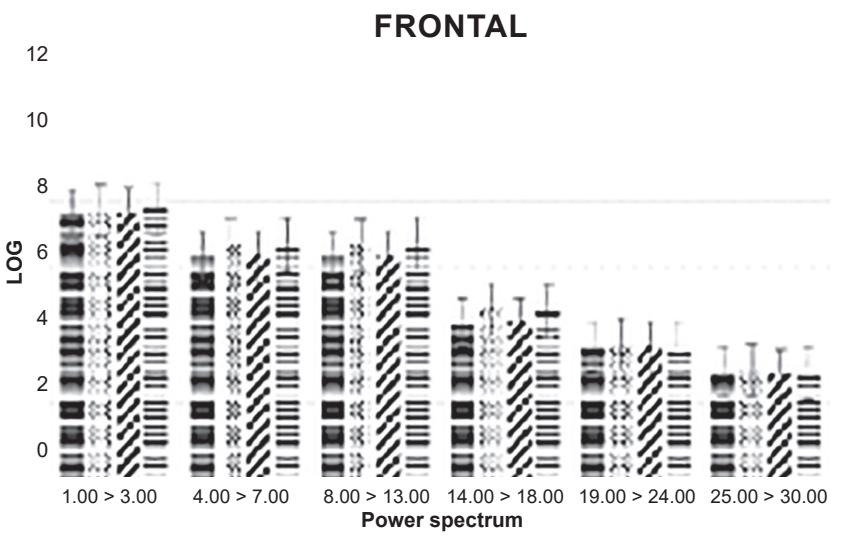

12

PARIETAL

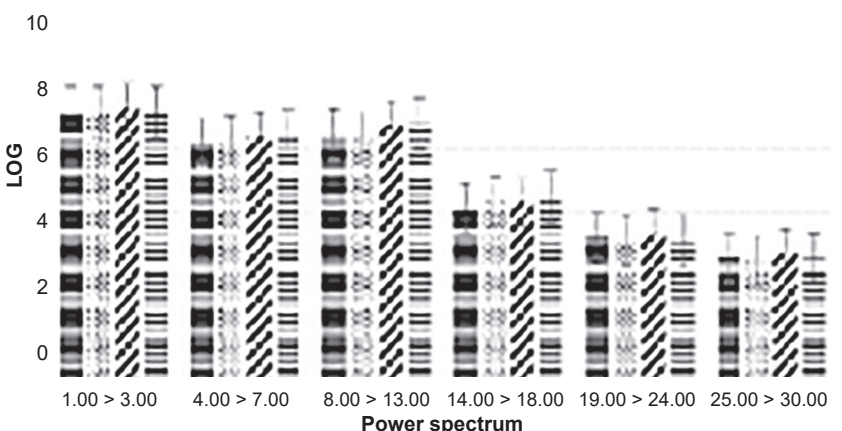

was a peak in the power spectrum in the $\mathrm{C}_{4}$ derivation, in the ASD group, the peak in the power spectrum was in $\mathrm{C}_{3}$.

The frequency of segments with $\mathrm{Mu}$ activity identified throughout the nocturnal polysomnographic record is given in Figure 3. It shows that the number of $\mathrm{Mu}$ segments detected was larger in the TD group, both overall and in each of the phases of sleep throughout the night. This difference is particularly clear during REM sleep, in the N1 and N2 phases (Figure 3).

12

CENTRAL

10

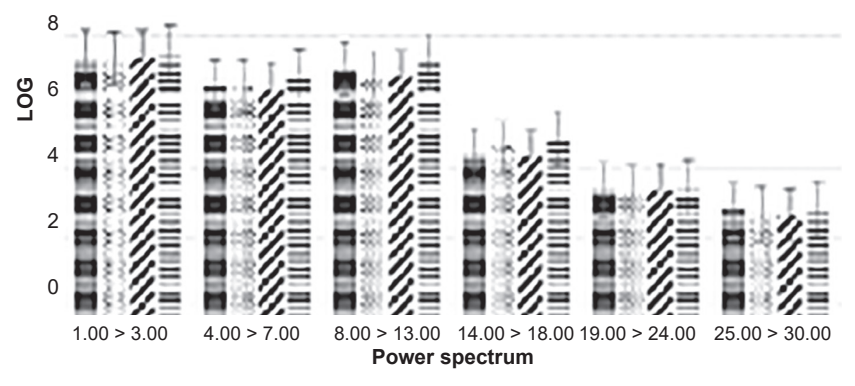

12

TEMPORAL

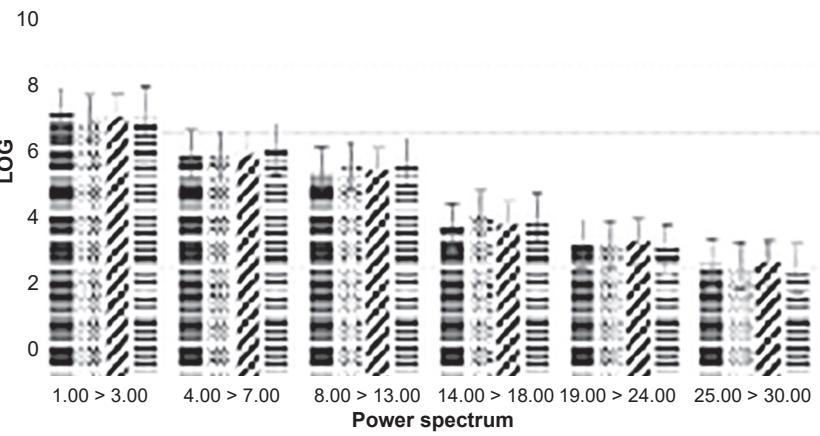

12

OCCIPITAL

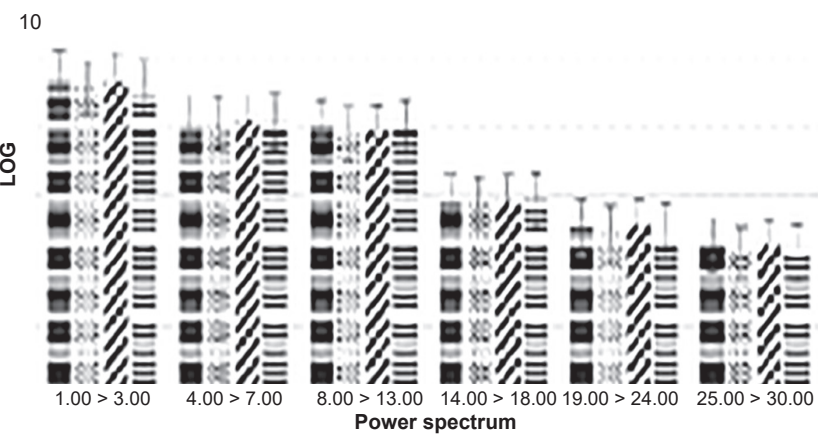

02 Control
02 ASD
01 Control
01 ASD

Figure 4. Average of absolute power spectrum of Mu segments organized by area.

Note: Average of the absolute power spectrum of Mu segments and the activity of the different bands analyzed, organized according to the area where the record was taken. The horizontal axis shows the frequencies and the vertical axis the power spectrum in logarithm analyzed by the Potencor program. The distribution of Mu activity can be seen topographically: higher in Frontal, Central and Parietal areas and lower in Occipital areas. Standard error is marked on each bar. 


\section{DISCUSSION AND CONCLUSION}

Although very few studies have characterized the $\mathrm{Mu}$ rhythm during the sleep of healthy subjects, the results of this paper coincide with those described by other authors during the REM sleep phase (Duntley et al., 2001; Marini, Ceccarelli, \& Mancia, 2008; Quan et al., 2003) and the N2 phase (Quan et al., 2003). However, in this study, it was observed that the Mu rhythm was more abundant in N2 than in REM, in comparison with the papers cited. These differences could be due to the methodology used, since in previous studies, electroencephalographic analyses were performed visually, whereas in this study, a quantitative analysis (FFT) was carried out in addition to a visual inspection to identify the Mu rhythm during sleep. Likewise, all the segments were analyzed according to the power spectrum. In this section, special care was taken to distinguish the $8-13 \mathrm{~Hz}$ band from the sigma $(14-18 \mathrm{~Hz})$, characteristic of the sleep spindles of the $\mathrm{N} 2$ phase. It is also important to mention that the sample size of the present study was a limitation since, due to the exclusion criteria, it was not possible to expand it.

Topographically, the $\mathrm{Mu}$ rhythm observed complied with the characteristics described in the literature: an arcshaped rhythm, with an acute negative and rounded positive component, within the frequency of $8-13 \mathrm{~Hz}$, expressed most intensely in somatosensory regions, specifically $\mathrm{C}_{3}$ and $\mathrm{C}_{4}$ (Niedermeyer \& Silva, 2004). This characteristic was fulfilled in both groups and in both brain hemispheres, meaning that it coincided with what has been described in the literature on the topographical distribution of the $\mathrm{Mu}$ rhythm during wakefulness and sleep (Duntley et al., 2001; Gastaut, Naquet, \& Gastaut, 1965; Gélisse \& Crespel, 2014; Hari \& Salmelin, 1997; Oberman et al., 2008; Pineda, 2005; Yamada \& Kooi, 1975) (As shown in Figure 4).
Graphologically, the Mu rhythm observed complied with the characteristics described in the literature: an arcshaped rhythm, with an acute negative and rounded positive component, within the frequency of $8-13 \mathrm{~Hz}$, expressed most intensely in somatosensory regions, specifically $\mathrm{C}_{3}$ and $\mathrm{C}_{4}$ (Hari \& Salmelin, 1997). The features observed resemble those found by Duntley et al. (2001), who visually identified the $\mathrm{Mu}$ rhythm during the REM sleep phase of epileptic patients. Although there are differences between the samples, it is possible to observe the characteristic graphological similarities of the rhythm. The features found were topographically distinguished from the alpha rhythm, in other words, they were only observed above the somatosensory region (Figure 5).

As for the interhemispheric differences found between the groups, a possible explanation could be posited on the basis of the characteristics attributed to each brain hemisphere. Self-motivated or learned behaviors and probabilistic reasoning are attributed to the left hemisphere (Parsons \& Osherson, 2001) selective attention, characterization of stimuli from the environment on the basis of one or a few details and selective routines (MacNeilage, Rogers, \& Vallortigara, 2009). Conversely, the right hemisphere is the site of the organism's detection and response to novel or unexpected stimuli, visospatial processing, behavior motivated by the environment, synthesis of global patterns, face recognition, and the interpretation of facial expressions linked to emotions (MacNeilage et al., 2009). Another study found alterations in the blood perfusion of the medial temporal lobe in the right hemisphere of individuals with ASD, which they associated with the obsessive characteristics in the repetitive behavior characteristic of this population (Ohnishi et al., 2000). Accordingly, in the case of ASD, it makes sense that the power spectrum increases in the left
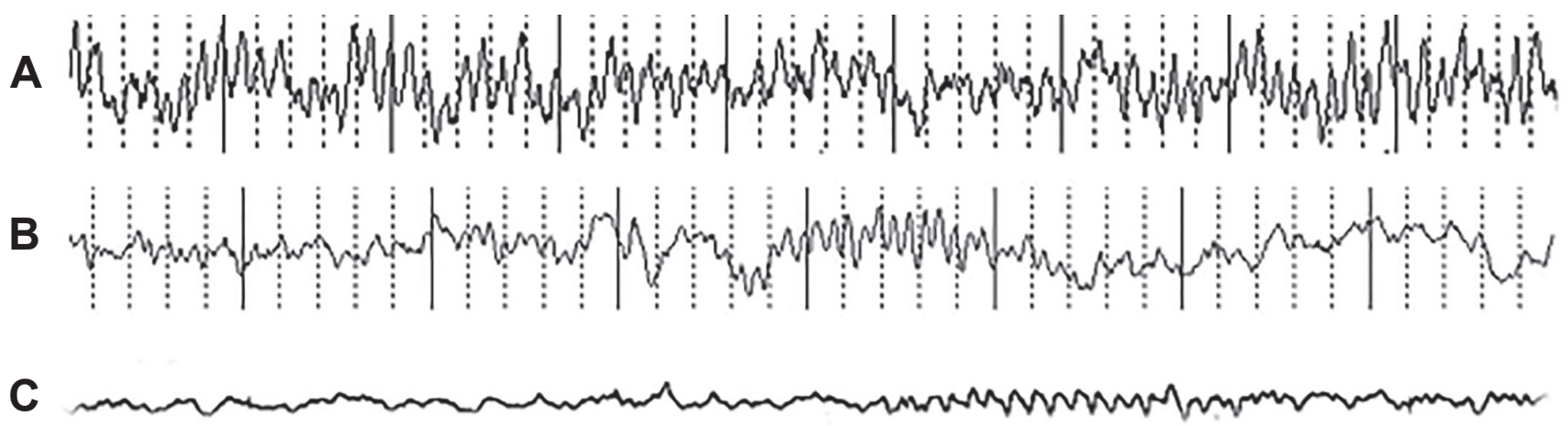

Figure 5. Comparison of Mu rhythm features observed.

Note: Comparison of Mu rhythm traces observed and their comparison with previous literature.

A. $=$ The feature of the Mu rhythm observed during wakefulness in an ASD participant is observed in $C_{4}$.

$B .=$ Feature of Mu rhythm observed during phase 2 of sleep in an ASD participant in $C_{3}$.

C. = Feature of Mu rhythm observed during the REM sleep phase in $\mathrm{C}_{3}$ adapted from Duntley et al., 2001.

In all cases, the Mu rhythm is identified by horizontal lines. 
hemisphere $\left(\mathrm{C}_{3}\right)$ and decreases in the right hemisphere $\left(\mathrm{C}_{4}\right)$, since it corresponds to the characteristics described in the population: repetitive, restricted behavior, good attention span, especially for details, affinity for carrying out routine activities, little ability to interpret facial expressions associated with emotions, aversion to changes or novel stimuli in already structured routines, etc. (American Psychiatric Association, 2013). Thus, the results obtained not only tally with previous literature on the Mu rhythm in this population during wakefulness, but also coincide with the other features described in the population with ASD.

This paper found significant differences in the spontaneous generation of Mu between a group of children with level 1 ASD and children with TD. This means that since this rhythm is produced intrinsically, it may be produced in response to external sensory stimulation (Yordanova \& Kolev, 1997). Within the context of various theories on ASD, the findings of this paper could contribute to the literature on possible neural foundations associated with understanding the mental state of others, in the case of TM. At the same time, within the theory of mirror neurons and ASD, the spontaneous generation of the Mu rhythm in the sleep of children with ASD could lead to therapeutic applications, if we consider that the $\mathrm{Mu}$ rhythm has also been regarded as an electroencephalographic index of the mirror neuron system in humans. These applications could expand the various existing therapeutic alternatives, involving behavioral neuroregulation and neuronal metabolic function techniques (Coben, Linden, \& Myers, 2010; Pineda et al., 2008). However, it is clear that more studies are required in this field to corroborate and expand existing information.

\section{Funding}

Funding from the PAPIIT IN223707-2 Project

\section{Conflict of interests}

The authors declare they have no conflict of interests.

\section{Acknowledgements}

Thanks are due to the Facultad de Psicología, Universidad Nacional Autónoma de México, and the Caritas de Amistad association for their collaboration in undertaking the project.

\section{REFERENCES}

American Psychiatric Association. (2013). Diagnostic and statistical manual of mental disorders. doi: 10.1176/appi.books.9780890425596.744053

Ayala-Guerrero, F., Mexicano, G., \& Huicochea-Arredondo, S. (2014). Sleep characteristics in children with autism spectrum disorder. Journal of Neurological Disorders \& Stroke, 2(3), 1070.

Bernier, R., Aaronson, B., \& McPartland, J. (2013). The role of imitation in the observed heterogeneity in EEG Mu rhythm in autism and typical development. Brain and Cognition, 82(1), 69-75. doi: 10.1016/j.bandc.2013.02.008

Bernier, R., Dawson, G., Webb, S., \& Murias, M. (2007). EEG Mu rhythm and imitation impairments in individuals with autism spectrum disorder. Brain and Cognition, 64(3), 228-237. doi: 10.1016/j.bandc.2007.03.004
Braadbaart, L., Williams, J. H. G., \& Waiter, G. D. (2013). Do mirror neuron areas mediate $\mathrm{Mu}$ rhythm suppression during imitation and action observation? International Journal of Psychophysiology, 89(1), 99-105. doi: 10.1016/j.ijpsycho.2013.05.019

Coben, R., Linden, M., \& Myers, T. E. (2010). Neurofeedback for autistic spectrum disorder: A review of the literature. Applied Psychophysiology and Biofeedback, 35(1), 83-105. doi: 10.1007/s10484-009-9117-y

Cortesi, F., Giannotti, F., Ivanenko, A., \& Johnson, K. (2010). Sleep in children with autistic spectrum disorder. Sleep Medicine, 11(7), 659-664. doi: 10.1016/j. sleep.2010.01.010

Dahl, R. E. (1996). The impact of inadequate sleep on children's daytime cognitive function. Seminars in Pediatric Neurology, 3(1), 44-50. doi: 10.1016/S10719091(96)80028-3

Duntley, S. P., Kim, A. H., Silbergeld, D. L., \& Miller, J. W. (2001). Characterization of the Mu rhythm during rapid eye movement sleep. Clinical Neurophysiology, 112(3), 528-531. doi: 10.1016/S1388-2457(00)00559-9

Frank, M. G., Issa, N. P., \& Stryker, M. P. (2001). Sleep enhances plasticity in the developing visual cortex. Neuron, 30(1), 275-287. doi: 10.1016/S08966273(01)00279-3

Gastaut, H., Naquet, R., \& Gastaut, Y. (1965). A study of the Mu rhythm in subjects lacking one or more limbs. Electroencephalography and Clinical Neurophysiology, 18(4), 720-721.

Gélisse, P. \& Crespel, A. (2014). Mu rhythm and rhythmic midtemporal discharges in REM sleep. Neurophysiologie Clinique, 2(44), 165-167. doi: 10.1016/j.neucli.2014.03.005

Guevara, M. A., Ramos, J., Hernández-González, M., Zarabozo, D., \& Corsi-Cabrera, M. (2003). POTENCOR: A program to calculate power and correlation spectra of EEG signals. Computer Methods and Programs in Biomedicine, 72(3), 241-250. doi: 10.1016/S0169-2607(02)00128-1

Hamilton, A. F. D. C. (2013). Reflecting on the mirror neuron system in autism: A systematic review of current theories. Developmental Cognitive Neuroscience, 3(1), 91-105. doi: 10.1016/j.den.2012.09.008

Hari, R. \& Salmelin, R. (1997). Human cortical oscillations: A neuromagnetic view through the skull. Trends in Neurosciences, 20(1), 44-49. doi: 10.1016/S01662236(96)10065-5

Hauswald, A., Weisz, N., Bentin, S., \& Kissler, J. (2013). MEG premotor abnormalities in children with Asperger's syndrome: Determinants of social behavior?. Developmental Cognitive Neuroscience, 5, 95-105. doi: 10.1016/j. den.2013.02.002

Johnson, K. P., Giannotti, F., \& Cortesi, F. (2009). Sleep Patterns in Autism Spectrum Disorders. Child and Adolescent Psychiatric Clinics of North America, 18(4), 917-928. doi: 10.1016/j.chc.2009.04.001

Lepage, J. F. \& Théoret, H. (2006). EEG evidence for the presence of an action observation-execution matching system in children. European Journal of Neuroscience, 23(9), 2505-2510. doi: 10.1111/j.1460-9568.2006.04769.x

MacNeilage, B. P. F., Rogers, L. J., \& Vallortigara, G. (2009). Origins of the Left \& Right Brain. Scientific American, 301(1), 60-67. doi: 10.1038/scientificamerican0709-60

Malow, B. A., Marzec, M. L., McGrew, S. G., Wang, L., Henderson, L. M., \& Stone, W. L. (2006). Characterizing sleep in children with autism spectrum disorders: a multidimensional approach. Sleep, 29(12), 1563-1571. doi: 10.1017/ S0012162204000611

Marini, G., Ceccarelli, P., \& Mancia, M. (2008). Characterization of the 7-12 Hz EEG oscillations during immobile waking and REM sleep in behaving rats. Clinical Neurophysiology, 119(2), 315-320. doi: 10.1016/j.clinph.2007.09.142

Niedermeyer, E. \& Silva, F. H. L. (2004). Electroencephalography: Basic Principles, Clinical Applications, and Related Fields. Lippincott Williams and Wilkins. Retrieved from: http://books.google.com/books?id=tndqYGPHQdEC\&pgis $=1$

Oberman, L. M., Hubbard, E. M., McCleery, J. P., Altschuler, E. L., Ramachandran, V. S., \& Pineda, J. A. (2005). EEG evidence for mirror neuron dysfunction in autism spectrum disorders. Cognitive Brain Research, 24(2), 190-198. doi: 10.1016/j.cogbrainres.2005.01.014

Oberman, L. M., Ramachandran, V. S., \& Pineda, J. A. (2008). Modulation of Mu suppression in children with autism spectrum disorders in response to familiar 
or unfamiliar stimuli: The mirror neuron hypothesis. Neuropsychologia, 46(5), 1558-1565. doi: 10.1016/j.neuropsychologia.2008.01.010

Ohnishi, T., Matsuda, H., Hashimoto, T., Kunihiro, T., Nishikawa, M., Uema, T., \& Sasaki, M. (2000). Abnormal regional cerebral blood flow in childhood autism. Brain, 123(9), 1838-1844. doi: 10.1093/brain/123.9.1838

Parsons, L. M. \& Osherson, D. (2001). New Evidence for Distinct Right and Left Brain Systems for Deductive versus Probabilistic Reasoning. Cerebral Cortex, 11(10), 954-65. doi: 10.1093/cercor/11.10.954

Pineda, J. A. (2005). The functional significance of Mu rhythms: Translating "seeing" and "hearing" into "doing." Brain Research Reviews, 50(1), 57-68. doi: 10.1016/j.brainresrev.2005.04.005

Pineda, J. A., Brang, D., Hecht, E., Edwards, L., Carey, S., Bacon, M., ... Rork, A. (2008). Positive behavioral and electrophysiological changes following neurofeedback training in children with autism. Research in Autism Spectrum Disorders, 2(3), 557-581. doi: 10.1016/j.rasd.2007.12.003

Pineda, J. A. \& Hecht, E. (2009). Mirroring and Mu rhythm involvement in social cognition: Are there dissociable subcomponents of theory of mind? Biological Psychology, 80(3), 306-314. doi: 10.1016/j.biopsycho.2008.11.003

Pivik, R. T., Broughton, R. J., Coppola, R., Davidson, R. J., Fox, N., \& Nuwer, M. R. (1993). Guidleines for the recording and quantitative analysis of electroencephalographic activity in research contexts. Psychophysiology, 30(6), 547-558.

Quan, S. F., Goodwin, J. L., Babar, S. I., Kaemingk, K. L., Enright, P. L., Rosen, G. M., ... Morgan, W. J. (2003). Sleep architecture in normal Caucasian and Hispanic children aged 6-11 years recorded during unattended home polysomnography: Experience from the Tucson Children's Assessment of Sleep Apnea Study (TuCASA). Sleep Medicine, 4(1), 13-19. doi: 10.1016/s1389-9457(02)00235-6

Ramachandran, V. S. \& Oberman, L. M. (2006). Broken mirrors: a theory of autism. Scientific American, 295(5), 62-69. doi: 10.1038/scientificamerican1106-62

Richdale, A. L. (1999). Sleep problems in autism: prevalence, cause, and intervention. Developmental Medicine and Child Neurology, 4l(1), 60-66. doi: 10.1017/ S0012162299000122
Rizzolatti, G. \& Craighero, L. (2004). The Mirror-Neuron System. Annual Review of Neuroscience, 27(1), 169-192. doi: 10.1146/annurev.neuro.27.070203.144230

Schreck, K. A., Mulick, J. A., \& Smith, A. F. (2004). Sleep problems as possible predictors of intensified symptoms of autism. Research in Developmental Disabilities, 25(1), 57-66. doi: 10.1016/j.ridd.2003.04.007

Souders, M. C., Mason, T. B. A., Valladares, O., Bucan, M., Levy, S. E., Mandell, D. S., ... Pinto-Martin, J. (2009). Sleep behaviors and sleep quality in children with autism spectrum disorders. Sleep, 32(12), 1566-1578. Retrieved from: http:// www.pubmedcentral.nih.gov/articlerender.fcgi?artid=2786040\&tool=pmcentrez\&rendertype $=$ abstract

Tirapu-Ustárroza, J. (2007). ¿Qué es la teoría de la mente?. Revista de Neurología, 44(8), 479-489. Retrieved from: http://www.uam.es/personal_pdi/psicologia/ cgil/eto y neuro/Tirapu-Ustarroz 2007.pdf

Vriend, J. L., Corkum, P. V., Moon, E. C., \& Smith, I. M. (2011). Behavioral interventions for sleep problems in children with autism spectrum disorders: Current findings and future directions. Journal of Pediatric Psychology, 36(9), 10171029. doi: $10.1093 /$ jpepsy/jsr044

Wiggs, L.\& Stores, G. (2004). Sleep patterns and sleep disorders in children with autistic spectrum disorders: insights using parent report and actigraphy. Developmental Medicine and Child Neurology, 46(6), 372-380. doi: 10.1017/ S0012162204000611

Williams, J. H. G., Waiter, G. D., Gilchrist, A., Perrett, D. I., Murray, A. D., \& Whiten, A. (2006). Neural mechanisms of imitation and "mirror neuron" functioning in autistic spectrum disorder. Neuropsychologia, 44(4), 610-621. doi: 10.1016/j. neuropsychologia.2005.06.010

Yamada, T. \& Kooi, K. A. (1975). Level of Consciousness and the Mu Rhythm. Clinical Electroencephalography, 6(2), 80-88. doi: 10.1177/155005947500600206

Yordanova, J. \& Kolev, V. (1997). Alpha response system in children: Changes with age. International Journal of Psychophysiology, 26(1-3), 411-430. doi: $10.1016 / \mathrm{S} 0167-8760(97) 00779-4$ 